\title{
THE ROLE OF UNPAVED ROADS IN THE SEDIMENT BUDGET OF A SEMI-ARID MESOSCALE CATCHMENT
}

\author{
Teresa Raquel Lima Farias ${ }^{1}$, Pedro Medeiros ${ }^{1}$, José Carlos de Araujo ${ }^{2}$, and Joaquin \\ Navarro Hevia ${ }^{3}$ \\ ${ }^{1}$ Federal Institute of Education, Science and Technology of Ceará \\ ${ }^{2}$ Federal University of Ceará \\ ${ }^{3}$ University of Valladolid
}

June 28, 2021

\begin{abstract}
High rates of erosion and runoff production on road infrastructure have been documented, indicating that unpaved roads might be significant sources of sediment in catchments. In this paper, the production of surface sediments from unpaved rural roads at different scales is assessed. The study took place in northeastern Brazil, in a semiarid area of the Caatinga biome, vulnerable to desertification. Sediment production data from road surface segments were monitored for two years (2013-2014) under conditions of natural precipitation. By using hydrosedimentological modeling and Geographic Information System (GIS), the sediment budget was calculated at the meso-scale basin (aprox. $930 \mathrm{~km}^{2}$ ), in order to identify the relative contribution of roads to the sediment balance. Universal Soil Loss Equation (USLE) associated with Maner's sediment delivery ratio (SDR) equation, proved to be an adequate approach for predicting sediment yield on the road segment scale; the best results were obtained for the road without traffic, due to the non-interference in this segment of external factors, such as traffic and maintenance activities, not explicitly considered in the model formulation. The modeling procedure showed that the roads, which occupy only $0.7 \%$ of the catchment surface, were responsible for approximately $7 \%$ of soil loss in the area. Furthermore, sediment connectivity might be enhanced by roads, which cross the river network and, therefore, deliver more directly the sediment generated at hillslopes. This is particularly important in the studied environment, where sediment connectivity is low due to limited runoff and the existence of a dense network of surface water reservoir
\end{abstract}

\section{Hosted file}

Farias et al_Submit_LDD.docx available at https://authorea.com/users/422351/articles/528071the-role-of-unpaved-roads-in-the-sediment-budget-of-a-semi-arid-mesoscale-catchment 

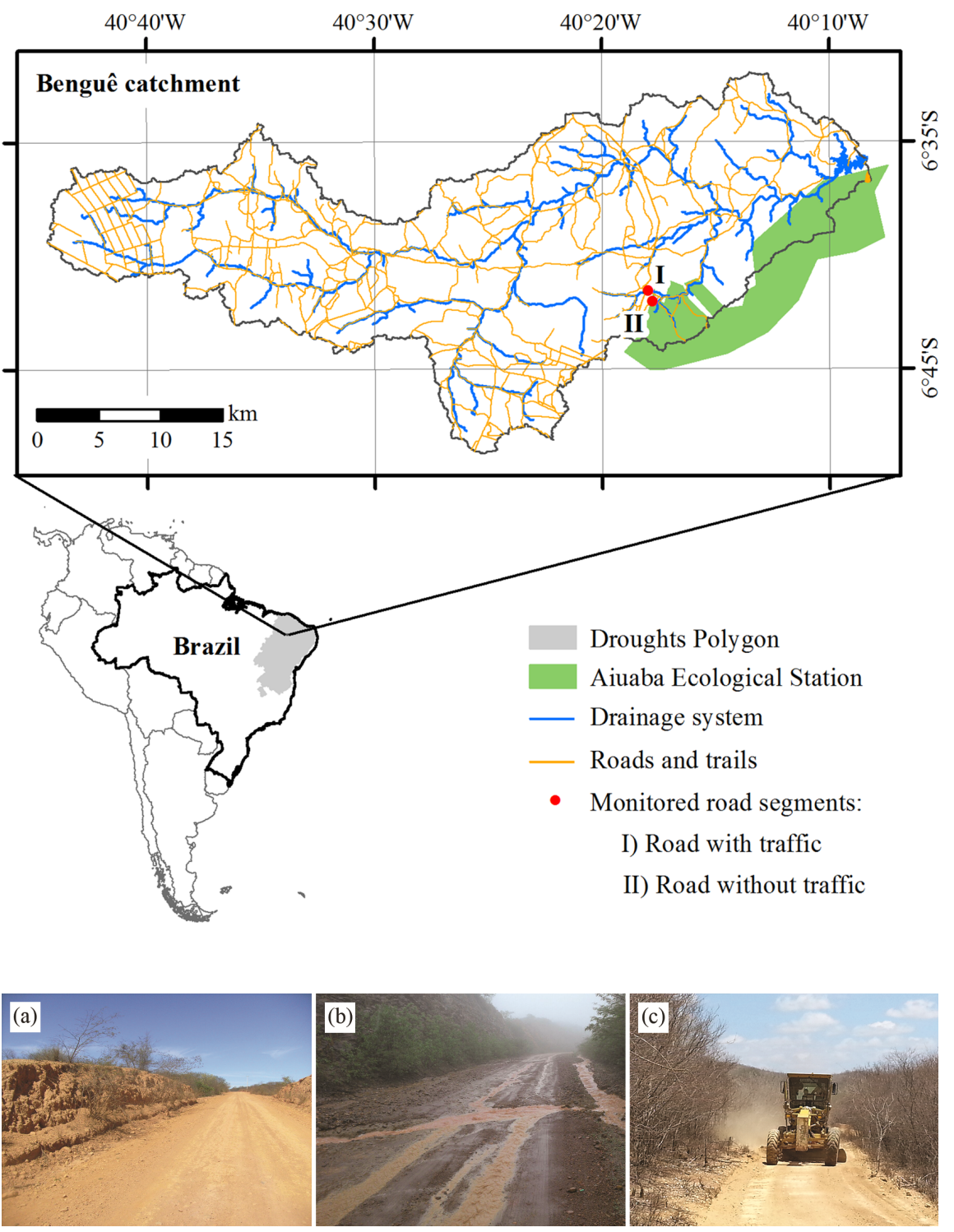


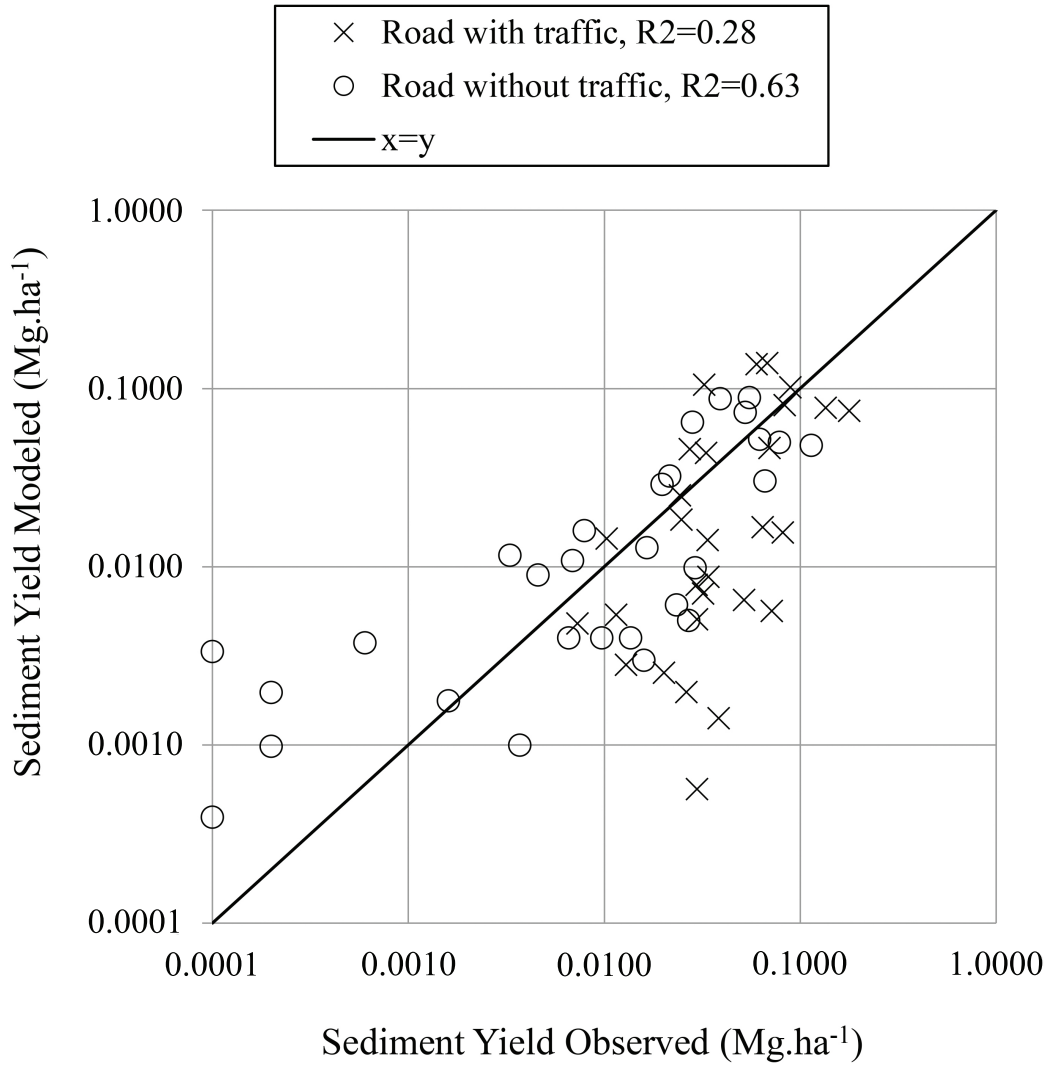

(a)
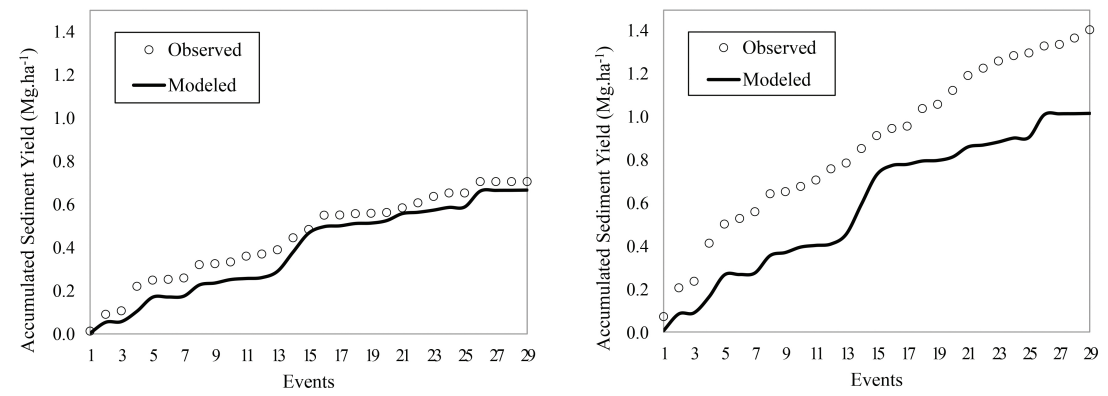


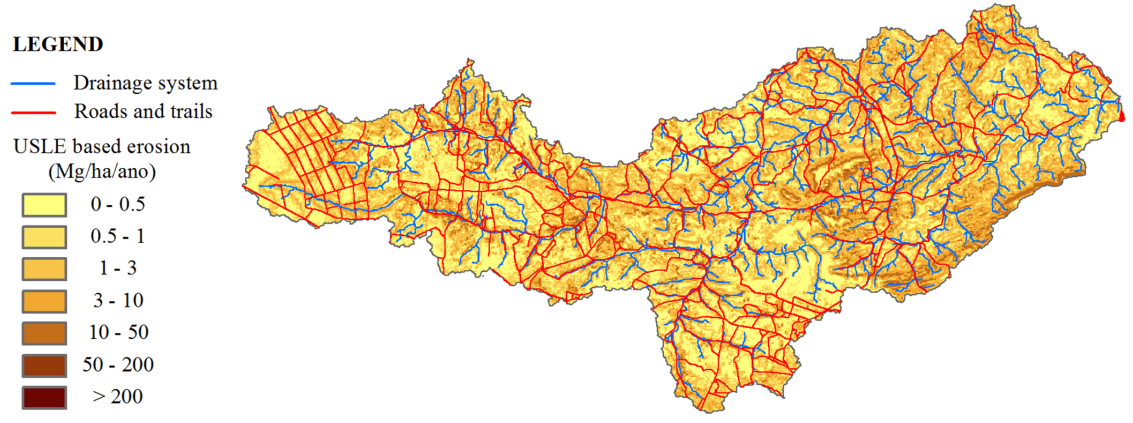

